\title{
Corrigendum
}

\section{Corrigendum to "Cre-loxP-based system for removal and reuse of selection markers in Ashbya gossypii targeted engineering" [Fungal Genet. Biol. 68 (2014) 1-8]}

\author{
Tatiana Q. Aguiar ${ }^{1}$, Cláudia Dinis ${ }^{1}$, Lucília Domingues*
}

CEB - Centre of Biological Engineering, University of Minho, 4710-057 Braga, Portugal

The authors regret, but the last sentence of the abstract should be read as: "In spite of its wide use in other organisms, including other Ascomycete fungi, this is the first report describing Cre-loxP-based methodology for A. gossypii, opening new perspectives for targeted engineering of this fungus with several promising biotechnological applications."

The authors would like to apologise for any inconvenience caused.

* Corresponding author. Fax: +351 253604400

E-mail address: luciliad@deb.uminho.pt (L. Domingues).

1 These authors contributed equally to this work. 